\title{
Evidence for selective target processing with a low perceptual load flankers task
}

\author{
LISE PAQUET and GREGORY L. CRAIG \\ Carleton University, Ottawa, Ontario, Canada
}

\begin{abstract}
In this article, we demonstrate that selective target processing is possible when the perceptual load of the task is low. We presented a row of three items with two different identities: one identity for the target letter and one for the two flankers (B. A. Eriksen \& C. W. Eriksen, 1974). Such stimulus arrays have been defined as low-load displays (Lavie \& Tsal, 1994). We investigated whether subjects could ignore the irrelevant flankers, which were never response alternatives, by manipulating the predictive relationship between the flankers and the response (Miller, 1987). In a high-correlation block, the identity of the flankers was highly predictive of the target identity, whereas in a lowcorrelation block, the predictive value of the flankers was reduced. We varied (1) whether or not the target location was precued, (2) the flanker's category (digit vs. letter), (3) the target-flanker proximity (near $=.3^{\circ}$ vs. far $=5^{\circ}$ ), and (4) the size of the characters. The results indicate that subjects were influenced by the predictive value of near flankers and that the magnitude of this effect was jointly modulated by the target-flanker categorical overlap and by the size of the characters. In contrast, null flanker effects were obtained for far letter flankers in the precue condition, and for far digit flankers, regardless of attentional cuing. These findings (1) are inconsistent with suggestions (Lavie, 1995) that irrelevant stimuli automatically capture attention, and (2) support the notion that targetflanker distinctiveness plays a role when the perceptual load of the task is low.
\end{abstract}

The question of knowing whether people can exclude distracting stimuli while responding to relevant ones has been a topic for studies of visual attention for at least 40 years. One widely used paradigm to investigate this issue has been the "flankers task" developed by B. A. Eriksen and C. W. Eriksen (1974). As illustrated in Table 1, the subject's task is to decide whether the middle letter of a three-letter array is, for example, an $\mathrm{H}$ or an I (target set). Flanking letters appearing within $1^{\circ}$ of visual angle on either side of the target must be ignored. The flankers, whose identity (flankers set) always corresponds to a target set item, either are identical to the target (compatible condition) or they represent the opposite target set item (incompatible condition). The classic result, termed "flanker compatibility effect" (FCE), is that subjects are slower under the incompatible than under the compatible condition. This finding supports the hypothesis that the selective mechanisms responsible for target processing are imperfect (Evans \& Craig, 1992; Kahneman \& Henik, 1981; Miller, 1987).

Recent experiments have demonstrated that the selectivity of target processing could be enhanced by increasing the physical distinctiveness between the target and the flankers. ${ }^{1}$ Thus, smaller FCEs have been reported with far flankers (i.e., target-flanker spatial separation larger

This research was supported by Grant A 1247 from the Natural Sciences and Engineering Research Council of Canada. Thanks are extended to Andrew Boos, Camille Husseini, and Yuntai $\mathrm{Wu}$ for their help with data collection. Correspondence should be addressed to L. Paquet, Department of Psychology, Carleton University, Ottawa, ON, Canada Kis 5B6 (e-mail: Ipaquet@eccs.carteton.ca). than $1^{\circ}$ ) than with near flankers (i.e., target-flanker separation within $1^{\circ}$ ). Similarly, the FCE was found to be curtailed when the target and the flankers could be perceptually segregated on the basis of motion or color differences or on the basis of good continuation. Although these studies illustrate the importance of physical distinction, one striking observation is that the FCE was only reduced and not eliminated under conditions of clear target-flanker physical distinction (Miller, 1991). This observation agrees with the notion that the selective mechanisms responding to the target are inherently limited and cannot avoid competition from the flankers.

Contrary to this hypothesis, however, recent research indicates that the selective processing deficits uncovered in the previously mentioned studies might have been the product of employing low perceptual load displays for which target processing does not require all of the available resources. Hence, Lavie (1995), using the flankers task paradigm, showed that the FCE associated with far flankers vanished under conditions of high perceptual load (i.e., the target was imbedded in displays of several different letters), whereas a robust FCE was found under conditions of low perceptual load (i.e., displays with only two different letters, one target and one flanker). These data suggest that competition from distant flankers can be avoided when all of the available processing resources are devoted to target processing. More critically for the present article, Lavie's data also imply that selective processing of the target might be impossible when target processing does not utilize all of the available processing resourees: "When the relevant stimuli do not demand all of the available capacity, irrelevant stimuli will uninten- 
Table 1

Examples of the Experimental Conditions and Stimulus Displays in B. A. Eriksen and C. W. Eriksen (1974), Miller (1987), and

Paquet and Lortie (1990)

\begin{tabular}{|c|c|c|c|c|}
\hline Study & Target Set & Flankers Set & Conditions & Examples \\
\hline \multicolumn{5}{|l|}{ B. A. Eriksen \& } \\
\hline C. W. Eriksen (1974) & H I & H I & $\begin{array}{l}\text { Compatible } \\
\text { Incompatible }\end{array}$ & $\begin{array}{lllll}\mathrm{H} & \mathbf{H} & \mathrm{H} / \mathrm{I} & \mathbf{I} & \mathrm{I} \\
\mathrm{I} & \mathrm{H} & \mathbf{I} / \mathrm{H} & \mathrm{I} & \mathrm{H}\end{array}$ \\
\hline \multirow[t]{2}{*}{ Miller (1987) } & H I & R P & Valid & R H R/P I P \\
\hline & & & Invalid & P H P/R I R \\
\hline \multirow[t]{2}{*}{ Paquet \& Lortie (1990) } & H I & 34 & Valid & $\begin{array}{lllll}3 & H & 3 / 4 & 1 & 4\end{array}$ \\
\hline & & & Invalid & 4 H $4 / 3$ I 3 \\
\hline
\end{tabular}

tionally capture spare capacity, consequently enabling their processing" (Lavie, 1995, p. 452).

However, some caution seems warranted before embracing Lavie's (1995) conclusion. In particular, the fact that most experiments investigating the FCE have used displays for which there was a complete overlap between the target and the flankers sets (see Table 1, top panel) is of some concern. Hence, it is possible to argue that clearly visible flankers that correspond to response alternatives may call attention to themselves (Schneider \& Fisk, 1984; Shiffrin \& Schneider, 1977), therefore attracting any residual processing resources and influencing target responding. In other words, flankers belonging to the target set may be difficult to select against because one of their key properties (i.e., their identity) is very similar to that of the target (Allport, 1989, 1993; Duncan, 1983). Presumably, flankers that do not belong to the target set might not attract spare resources and might not influence target processing.

Miller (1987) assessed the role of set overlap by presenting letter flankers that were never used as response alternatives. As shown in Table 1, middle panel, low-load displays consisting of three letters were employed and subjects were required to identify only the middle letterfor example, $\mathrm{H}$ or $\mathrm{I}-$ while ignoring the flankers $(\mathrm{R}$ or P). It is important to note that the absence of overlap between the target and the flankers sets precludes an assessment of the FCE requiring that the flankers belong to the target set. Therefore, in order to determine whether or not the flankers influenced target responding, Miller developed the "correlational cuing paradigm," in which the flanker's identity serves as a cue for the correct response. For example, an $\mathrm{H}$ target might be presented more often with $\mathrm{R}$ flankers (see Table 1, valid condition) than with $\mathrm{P}$ flankers (see Table 1, invalid condition). Therefore, the presence of $R$ flankers could serve as a valid cue for an "H" response. Similarly, an I target might appear more often with $P$ flankers (see Table 1, valid condition) than with $\mathrm{R}$ flankers (see Table 1, invalid condition), making an "I" response more likely to be correct when $\mathrm{P}$ flankers were displayed. The results showed that, for a high correlation block where $92 \%$ of the trials were validly cued, targets presented with valid flankers were responded to faster than those appearing with invalid flankers. This effect, referred to as the "flanker validity effect" (FVE), suggests that the irrelevant flankers influenced target processing. In addition, the FVE was not observed for a low-correlation block, where only $58 \%$ of the trials displayed valid flankers. Therefore, contrary to our earlier suggestion, target and distractor set overlap does not appear to be responsible for the robust flanker effects observed previously with low-load displays.

However, Miller's (1987) results are not totally convincing because poor target-flanker distinction may have reduced the efficiency of selective target processing. To examine this possibility, Paquet and Lortie (1990) improved the selection conditions in Miller's correlational cuing paradigm. First, on the basis of previous suggestions that categorical cues can enhance selective target processing (Allport, 1989), subjects identified letter targets in the presence of either letter flankers (Table 1, middle panel) or digit flankers (Table 1, bottom panel). Second, Paquet and Lortie contrasted whether or not a fixation cross informed subjects in advance of the precise target location. The results showed that the FVE associated with letter flankers was smaller when a precue directed attention in advance to the precise target location than when, as in Miller's study, no cue was used. Moreover, under no-cue conditions, a reduction in the FVE occurred if digits instead of letters were used as flankers. These findings confirm that the efficiency of selective processing is modulated by factors such as visual precue (Fournier, 1994) or categorical contrast (Broadbent, 1982; Johnston \& Dark, 1986; Yantis \& Johnston, 1990), presumed to enhance target-flanker distinctiveness.

However, as noted by Lavie and Tsal (1994), the FVE was only reduced and not eliminated by the manipulations Paquet and Lortie (1990) designed to improve targetflanker distinctiveness. Such robustness of the FVE can be viewed as evidence that selective processing of the target is impossible with low-load displays (Lavie, 1995; Miller, 1991). Alternatively, the conditions for efficient target selection might have remained suboptimal in $\mathrm{Pa}$ quet and Lortie's experiment because the flankers were located only $0.3^{\circ}$ away from the target (Yantis \& Johnston, 1990). Therefore, the hypothesis that previous failures to eliminate the influence of flankers with low-load displays was the outcome of an overlap between the target and the flankers set has yet to be tested stringently under conditions of clear target-flanker distinctiveness. 


\section{EXPERIMENT 1}

Experiment 1 was designed to test whether Paquet and Lortie's (1990) failure to eliminate the FVE was due to the close proximity $\left(.3^{\circ}\right)$ between the target and the flankers. Therefore, a replication of Paquet and Lortie's study was undertaken with the addition of a target-flanker separation manipulation that was $0.3^{\circ}$ for the near flankers conditions and $5^{\circ}$ for the far flankers conditions. For each level of target-flanker separation, the correlational cuing paradigm developed by Miller (1987) was replicated under four testing conditions that contrasted whether or not a fixation point preceded each stimulus display (cue vs. no-cue), and whether the flankers were letters or digits. Within each testing condition, the FVE was assessed as a function of the strength of the flankers-response correlation, which was equal to .92 and .58 for the highand low-correlation levels, respectively.

On the basis of previous low-load studies, we predicted that subjects would be incapable of selectively processing the target presented with near flankers. More critical was the far target-flanker separation condition, which should greatly improve target-flanker distinctiveness and promote selective processing of the target. Consequently, null effects of far flankers were expected.

\section{Method}

Subjects. Three hundred and eighty-four students from Carleton University participated in a single session lasting $45 \mathrm{~min}$.

Design. The experimental design was a $2 \times 2 \times 2 \times 2 \times 2$ mixed factorial. Target-flanker separation $\left(.3^{\circ}\right.$ vs. $\left.5^{\circ}\right)$, target location precuing (cue vs. no-cue), and flankers category (letters vs. digits) were the between-subjects factors; flanker-response correlation strength and flanker validity were the within-subjects factors. Forty-eight subjects were randomly assigned to each combination of the levels of the between-subjects factors.

Apparatus and Stimuli. The stimulus arrays were viewed from a distance of $30 \mathrm{~cm}$ and were displayed in the center of an 11 -in.wide Zenith ZCM-1490 monitor. The subjects responded by pushing one of two buttons (either the 1 or the 0 key at the top of the keyboard) with the index finger of each hand.

Each stimulus display consisted of a letter target flanked by a distractor on each side. The edge-to-edge separation between the target and the flankers was $.3^{\circ}$ in the near conditions and $5^{\circ}$ in the far conditions. Following Miller's (1991) recommendation, we used very large character size in order to decrease the likelihood that any disappearance of the FVE in the far conditions could be linked to inadequate visibility of the far flankers. Therefore, the character's height was $4^{\circ}$ of visual angle and the character's width was $1.9^{\circ}$ for the near and far conditions. ${ }^{2}$ Furthermore, in order to avoid target selection based on a size difference between the target and the flankers, all characters displayed in the array were the same size

Procedure. Each subject served in two blocks of 192 trials each. For each level of flankers category, six characters (six letters for letter flankers conditions; four letters and two digits for digit flankers conditions) were randomly chosen at the beginning of each block, with the requirement that a different set be employed for each block. Of these characters, four letters were designated as targets (two assigned to the left-hand response, two to the right-hand response), and the remaining two characters were used as flankers. As shown in Table 2, a total of eight stimulus arrays (four valid and four invalid) were used for each block. For the high-correlation block, the flankers validly cued the correct response for 176 trials (four arrays each presented 44 times, see Table 2), whereas for the
Table 2

Sample Arrays and Number of Trials per Stimulus Array in Experiment 1

\begin{tabular}{|c|c|c|c|}
\hline \multirow{2}{*}{$\begin{array}{l}\text { Flanker } \\
\text { Validity }\end{array}$} & \multirow[b]{2}{*}{ Sample Arrays } & \multicolumn{2}{|c|}{ Correlation } \\
\hline & & High & Low \\
\hline Valid & $6 \mathrm{H} 6 \quad 616 \quad 5 \mathrm{~K} 5 \quad 5 \mathrm{P} 5$ & 44 & 28 \\
\hline Invalid & $\begin{array}{lllll}5 \mathrm{H} 5 & 515 & 6 \mathrm{~K} 6 & 6 \mathrm{P} 6\end{array}$ & 4 & 20 \\
\hline
\end{tabular}

Note-The six selected characters of the above example are HIKP56, with $\mathrm{HI}$ versus KP as targets, and 5 and 6 as digit flankers.

remaining 16 trials, invalid flankers arrays were presented. In contrast, for the low-correlation block, there were 112 validly cued trials (four arrays each presented 28 times) and 80 invalidly cued trials The order of presentation of the valid and invalid trials was randomized. Half of the subjects first received the low-correlation block and the other half participated in the high-correlation block first.

The procedure for the no-cue groups was as follows: Subjects were informed that a linear array of three characters would be presented at the center of the screen. They were required to identify the letter displayed in the middle of the array and to ignore the other characters. In contrast, subjects in the cued groups saw a fixation cross displayed at the center of the screen, in the same spatial location as the target, at the beginning of each trial. When subjects pressed the space bar, the fixation cross was replaced by a linear array of three characters, and subjects were required to identify the letter displayed at fixation, in the middle of the array and to ignore the other characters. For both cuing conditions, the stimulus display remained on until the subject responded or until $10 \mathrm{sec}$ had elapsed (Miller, 1987; Paquet \& Lortie, 1990). Accuracy feedback was presented for $1 \mathrm{sec}$ at the end of each trial. Subjects were instructed to respond quickly and accurately.

\section{Results and Discussion}

In each experiment of the present article, error and response time (RT) analyses were conducted. Because the results of the error analyses generally mirrored those of the RT data and because errors were few (approximately $96 \%$ correct responses for each study), only RT data will be presented. All of the RTs, their associated error rate, and the FVE are listed in Appendices A and B, for the cue and no-cue conditions, respectively.

For each subject and each testing condition, a flanker validity score was computed by subtracting the valid trials mean latency from the invalid trials mean latency. ${ }^{3}$ The FVEs observed for low-correlation blocks failed to reach significance and will not be discussed further. The $95 \%$ confidence intervals for the FVE obtained for the highcorrelation blocks for the cue and no-cue testing conditions are plotted in Figure 1. The figure shows that for the cued conditions, the FVE was affected by target-flanker separation $\left[F(1,188)=5.52, M S_{\mathrm{e}}=1,622, p<.05\right]$, with reliable FVEs being confined to the near $\left(.3^{\circ}\right)$ flankers conditions (see Appendix A for $p$ values). Therefore, when attention is well focused on the target location, it is possible to eliminate the FVE by increasing the distance separaing the target and the flankers. ${ }^{4}$ However, a different picture emerged for the no-cue conditions. As shown in Figure 1, no reliable target-flanker separation effect was obtained for letter flankers, and the FVE was reliable for both near $\left(.3^{\circ}\right)$ and far $\left(5^{\circ}\right)$ flankers conditions (see 


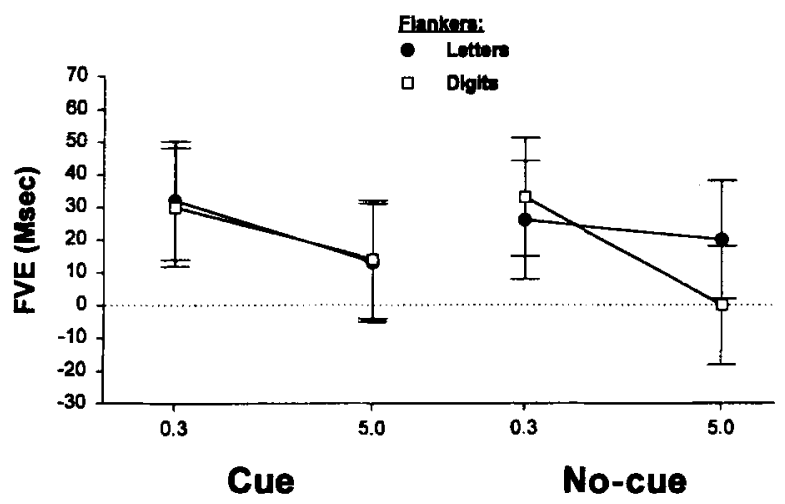

Figure 1. Flanker validity effect (FVE) for the cue (left lines) and no-cue (right lines) conditions for Experiment 1 as a function of target-flankers separation and flankers category.

Appendix B for $p$ values). In contrast, Figure 1 shows that target-flanker separation was an influential factor for digit flankers $\left[F(1,94)=9.17, M S_{\mathrm{e}}=2,680, p<.01\right]$, the FVE being eliminated for the far flankers condition (see Appendix B for the $p$ values). These findings indicate that when attention is not well focused on the target location, attentional capture by irrelevant far flankers can occur on the basis of a simple categorical overlap between the target and the flankers. However, attentional capture by irrelevant flankers can be prevented if a categorical contrast distinguishes the target and the flankers. Therefore, contrary to Lavie's (1995) hypothesis, attentional capture by irrelevant distractors does not appear to be automatic.

An unexpected aspect of the no-cue results is that the FVE associated with near letter flankers $(26 \mathrm{msec})$ was smaller than what has been typically observed under similar conditions by Miller $(1987 ; 60 \mathrm{msec})$ and by Paquet and Lortie (1990; $50 \mathrm{msec})$. Because of this reduced effect, the present results do not corroborate previous reports (Paquet \& Lortie, 1990) that the effect of near flankers was curtailed when a categorical difference existed between the target and the flankers.

The only procedural difference between the near letter flankers no-cue condition of the present experiment and previous studies (Miller, 1987; Paquet \& Lortie, 1990) concerns the character size. Hence, in order to ensure adequate visibility of the far flankers, the height of each character was increased from $1.5^{\circ}$ in Paquet and Lortie's study to $4^{\circ}$ in Experiment 1. In Experiment 2, we tested whether character size was responsible for the reduced near letter flanker effect observed in the no-cue condition.

\section{EXPERIMENT 2}

Experiment 2 was an attempt to evaluate the role of character size in our failure to replicate previous findings that a categorical distinction between the target and the near flankers reduces the flanker effect under no-cue conditions. We manipulated character size by using the char- acter set from Paquet and Lortie (1990) for one group of subjects (small size condition; $1.5^{\circ} \mathrm{high}$ ), and that of Experiment 1 for another group (large size condition; $4^{\circ}$ high). Furthermore, as in Experiment 1, we manipulated flankers category. If character size is important, then, for small characters, we should replicate the results of Paquet and Lortie and observe that the magnitude of the FVE is larger with letter than with digit flankers. Moreover, as we found in Experiment 1, the FVE should not be affected by flankers category for large characters.

\section{Method}

Subjects. One hundred ninety-two students from Carleton University participated in a single session lasting $45 \mathrm{~min}$.

Design. The experimental design was a $2 \times 2 \times 2 \times 2$ mixed factorial. Character size (small vs. large) and flankers category (letters vs. digits) were the between-subjects factors; flankerresponse correlation strength and flanker validity were the withinsubjects factors. Forty-eight subjects were randomly assigned to each combination of the levels of the between-subjects factors.

Apparatus and Stimuli. The stimuli for the small character set were identical to those used by Paquet and Lortie (1990). Each stimulus display consisted of a string of three alphanumeric characters, each $1.52^{\circ}$ high and $1.2^{\circ}$ wide. The stimuli for the large character set were identical to those used in Experiment 1 and measured $4^{\circ}$ high and $1.9^{\circ}$ wide. For each character size condition, only near flankers (target-flanker separation of $.3^{\circ}$ ) were employed under a no-cue condition.

Procedure. The procedure was identical to that of the no-cue conditions of Experiment 1. Subjects were informed that a linear array of three characters would be presented at the center of the screen, and they were required to identify the letter displayed in the middle of the array and to ignore the other characters. The stimulus display remained on until the subject responded or until $10 \mathrm{sec}$ had elapsed.

\section{Results and Discussion}

All of the RTs, their associated error rate, and the FVE are listed in Appendix C. The FVE effect ${ }^{5}$ for the highcorrelation blocks is illustrated in Figure 2. As is clear from this figure, character size influenced whether or not flankers category modulated the FVE. Thus, replicating Paquet and Lortie's (1990) results, the FVE was larger

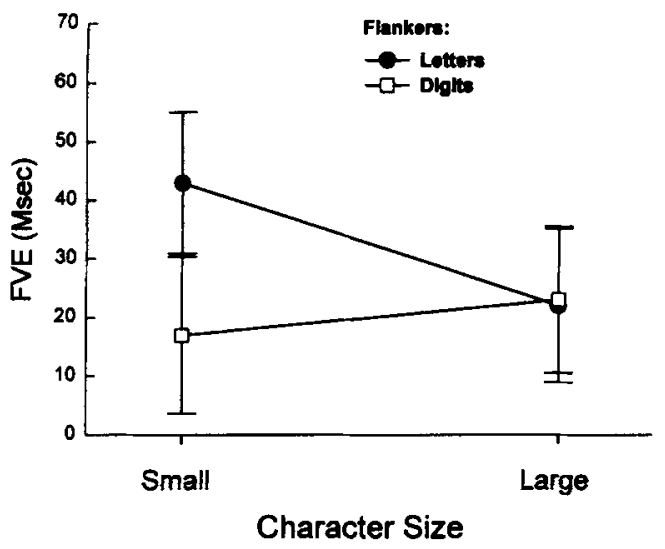

Figure 2. Flanker validity effect (FVE) for Experiment 2 as a function of character size and flankers category. 
for letter than for digit flankers for small character size $\left[F(1,94)=8.32, M S_{\mathrm{e}}=2,032, p<.01\right]$. On the other hand, as for Experiment 1, the FVE was unaffected by flanker category for large character size $(F<1)$.

One possible account of the present data is that small targets may be more difficult to locate and to select than large targets, particularly when surrounded by letter flankers. In support of this notion, the present results indicate that it was easier to select against letter flankers with large $(\mathrm{FVE}=22 \mathrm{msec})$ than with small $(\mathrm{FVE}=$ $43 \mathrm{msec})$ characters $\left[F(1,94)=5.57, M S_{\mathrm{e}}=995.3, p<\right.$ $.01]$. However, the data also show that the distinctiveness of small targets can be enhanced by introducing a categorical contrast between the target and the flankers, making it easier to select against digit flankers than against letter flankers. Moreover, the results suggest that when target location is accurately coded as a result of larger character size, then no extra benefits are derived from having a categorical contrast between the target and the flankers. Hence, the FVE was not influenced by the flankers category for the large character size. This finding is reminiscent of Paquet and Lortie's (1990) result showing that the magnitude of FVE for near flankers was affected only by flanker category under no-cue conditions, where, presumably, the conditions for efficient selection were suboptimal.

In sum, the crucial result of this experiment is to verify that using large character size contributed to our failure to replicate Paquet and Lortie's (1990) finding that categorical contrast between the target and the flankers is an important factor that modulates the size of the FVE when attention is not predirected to the target location.

\section{GENERAL DISCUSSION}

The main objective of the present studies was to examine a proposal formulated by Lavie and Tsal (1994) and by Lavie (1995) according to which the robustness of the flanker effect reported in many studies is linked to the low perceptual load associated with the stimulus arrays employed. According to these authors, target processing in the present low-load displays, which were composed of three items with only two different identities, should not utilize all of the available processing resources. Because perceptual processing "proceeds automatically until it runs out of capacity" (Lavie \& Tsal, 1994, p. 185), and because spare capacity is made available with low-load displays, the flankers should have automatically attracted available resources and influenced performance. In contrast with this view, the present study, using clearly visible far flankers, showed that it is possible to eliminate flanker effects with low-load displays. Therefore, it appears that selective target processing is possible with lowload displays, and that, under appropriate conditions, the flankers will not capture attention.

A second aim of the present studies was to evaluate the role of presenting flankers whose identity corresponds to one of the assigned response, in the flankers task (Miller, 1987). The results corroborated Miller's find- ings that using flankers that are not response alternatives is insufficient to eliminate flanker effects. Thus, substantial FVEs were obtained for letter and digit flankers that were in close proximity $\left(.3^{\circ}\right)$ to the target, and for far letter flankers when attention was not predirected to the target location. However, the present results demonstrate that target-flanker categorical overlap plays an important role in flanker effects. Thus, far flankers that were categorically distinct from the target could be successfully ignored, regardless of whether attention was predirected to the target location. On the other hand, whether or not it was possible to ignore far flankers from the same category as the target was modulated by how well attention was focused on the target location. In sum, the present data are consistent with the notion that target-flanker categorical overlap may contribute to flanker effects, especially when attention is not predirected to the precise target location.

Although there are several procedural differences between the experiments reported here and Lavie's (1995) study, the results just described suggest that target-flanker categorical overlap may have contributed to Lavie's observation of substantial flanker effects with her low-load displays. Thus, in her study attention was not precued to the precise target location, and the flankers that corresponded to one of the assigned responses belonged to the same semantic category as the target. The results indicate that substantial flanker effects are obtained under such conditions. Furthermore, the generality of Lavie's lowload results is also called into question by the observation that the flankers influence was eliminated when either a precue was used (letter flankers cued condition of Experiment 1) or when the target and the flankers were categorically distinct (digit flankers no-cue condition of Experiment 1). In sum, although Lavie's low-load hypothesis may provide a satisfactory explanation of many studies in which there was complete overlap between the targets and the flankers sets, the present data suggest that one of its central assumptions concerning the automatic capture of spare capacity by irrelevant stimuli should be revised.

\section{Target-Flanker Distinctiveness and \\ Flankers Filtering}

The results of the present study are in accordance with the notion that, at least for low-load displays, the efficiency of target processing and the ease of distractors filtering are determined by target-distractor distinctiveness (Allport, 1989; Baylis \& Driver, 1992; Duncan, 1989). First, the near flankers might have been difficult to select against because they resembled the target closely on the attribute of location (Baylis \& Driver, 1992). Thus, substantial FVEs were always obtained when the target and the flankers were separated by $.3^{\circ}$ of visual angle. Second, although the near flanker effect was quite robust, several factors modulated its magnitude. Thus, the results of Experiment 2, using small size characters and no-cue, confirmed that the FVE is lessened by providing a categorical contrast between the target and the flankers (Paquet \& Lortie, 1990). Furthermore, Experiment 2 
demonstrated that letter flanker effects can also be reduced simply by increasing the size of the characters being displayed. These results suggest that physical and conceptual differences both contribute to enhance targetflanker distinctiveness (Duncan, 1980, 1981, 1983).

In accordance with many prior low-load studies (see, e.g., Lavie \& Tsal, 1994), the present results demonstrated that, although necessary, large target-flanker separation was not sufficient to eliminate the flanker effect. Thus, it was found that whether or not far flankers influenced target processing was a joint function of targetflanker categorical overlap and target location precuing. When attention was precued, moving the flankers away from the target was sufficient to eliminate the flanker effect, regardless of the categorical overlap between the target and the flanker. Similarly, when a categorical contrast between the target and the flankers was provided, moving the flankers away from the target was sufficient to eliminate the flanker effect, regardless of attentional cuing. In contrast, the elimination of far letter flankers' effects required that attention be directed in advance to the target location. What this pattern of data suggests is that an optimal level of target-flanker distinction may depend on combining two selection schedules (Duncan, 1981). Thus, null flanker effects required large targetflanker separation (location selection) in addition to providing either (1) flankers from a different alphanumeric class than the target (categorical selection) or (2) attentional precue to the target location (object selection, Fournier, 1994). Previous studies using far flankers (location schedule) failed to precue attention or/and to use flankers from a different alphanumeric class than that of the target. This may account for the reported failures to eliminate flanker effects under conditions believed to promote clear target-flanker distinction.

\section{Conclusion}

The central idea of this paper was to observe whether flanker effects could be eliminated in low-load situations by optimizing the selection conditions. The present findings demonstrated that it is possible to obtain null effects from far flankers when either a categorical contrast distinguished the target and the flankers or when attention was precued to the target location. We are not questioning previous demonstrations ${ }^{6}$ that increasing the processing resources required for target processing may contribute to eliminate the flankers's influence. Our major claim and the thrust of the present paper is that the elimination of the effects of far flankers is not restricted to high perceptual load conditions, but can also be obtained with lowload displays. Our results suggest that one key factor is not simply how much spare resources are made available from target processing, but also whether or not distractor stimuli capture these resources. Our data suggest that attentional capture is not automatic, but is more likely to occur with crowded displays (near distractors) or when far flankers belong to the same alphanumeric class as the target and when attention is not predirected to the target location.

\section{REFERENCES}

Allport, D. A. (1989). Visual attention. In M. 1. Posner (Ed.), Foundations of cognitive science (pp. 631-682). Cambridge, MA: MIT Press. ALLPORT, D. A. (1993). Attention and control: Have we been asking the wrong questions? A critical review of 25 years. In D. E. Meyer \& S. Kornblum (Eds.), Attention and performance XIV (pp. 183-218). Cambridge, MA: MIT Press.

Baylis, G. C., \& Driver, J. (1992). Visual parsing and response competition: The effect of grouping factors. Perception \& Psychophysics, 51, 145-162.

BROADBENT, D. E. (1982). Task combination and selective intake of information. Acta Psychologica, 50, 253-290.

Dark, V. J., Johnston, W. A., Myles-Worsley, M., \& Farah, M. J. (1985). Levels of selection and capacity limits. Journal of Experimental Psychology: General, 114, 472-497.

Driver, J., \& BayLIS, G. C. (1989). Movement and visual attention: The spotlight metaphor breaks down. Journal of Experimental Psychology: Human Perception \& Performance, 15, 448-456.

DunCaN, J. (1980). The locus of interference in the perception of simultaneous stimuli. Psychological Review, 87, 272-300.

DunCan, J. (1981). Directing attention in the visual field. Perception \& Psychophysics, 30, 90-93.

DUNCAN, J. (1983). Category effects in visual search: A failure to replicate the "oh-zero" phenomenon. Perception \& Psychophysics, 34, $221-232$

DUNCAN, J. (1989). Boundary conditions on parallel processing in human vision. Perception, 18, 457-469.

ERIKSEN, B. A., \& ERIKSEN, C. W. (1974). Effects of noise letters upon the identification of a target letter in a nonsearch task. Perception \& Psychophysics, 16, 143-149.

ERIKSEN, C. W., \& ErIKSEN, B. A. (1979). Target redundancy in visual search: Do repetitions of the target within the display impair processing? Perception \& Psychophysics, 26, 195-205.

ERIKSEN, C. W., \& ST. JAMES, J. D. (1986). Visual attention within and around the field of focal attention: A zoom lens model. Perception \& Psychophysics, 40, 225-240.

Evans, P. M., \& Craig, J. C. (1992). Response competition: A major source of interference in a tactile identification task. Perception \& Psychophysics, 51, 199-206.

FOURNIER, L. R. (1994). Selective attentional delays and attentional capture among simultaneous visual onset elements. Perception \& Psychophysics, 56, 536-550.

Gathercole, S. E., \& Broadrent, D. E. (1987). Spatial factors in visual attention: Some compensatory effects of location and time of arrival of nontargets. Perception, 16, 433-443

GoolKasian, P. (1994). Size scaling and its effect on letter identification. Perception \& Psychophysics, 56, 681-690.

HaRms, L., \& BUndesen, C. (1983). Color segregation and selective attention in a nonsearch task. Perception \& Psychophysics, 33, 11-19.

Johnston, W. A., \& DARK, V. J. (1986). Selective attention, Annual Review of Psychology, 37, 43-75.

KAHNEMAN, D., \& CHAJCZYK, D. (1983). Tests of the automaticity of reading: Dilution of Stroop effects by color-irrelevant stimuli. Journal of Experimental Psychology: Human Perception \& Performance, 9, 497-509.

KahNeman, D., \& HeNik, A. (1981). Perceptual organization and attention. In M. Kubovy \& J. R. Pomerantz (Eds.), Perceptual organization (pp. 181-211). Hillsdale, NJ: Erlbaum.

LABERGE, D. (1983). Spatial extent of attention to letters and words Journal of Experimental Psychology: Human Perception \& Performance, 9, 371-379.

Laberge, D., Brown, V., Carter, M., Bash, D., \& Hartley, A. (1991). Reducing the effects of adjacent distractors by narrowing attention. Journal of Experimental Psychology: Human Perception \& Performance, 17, 65-76. 
Lavie, N. (1995). Perceptual load as a necessary condition for selective attention. Journal of Experimental Psychology: Human Perception \& Performance, 21, 451-468.

Lavie, N., \& Tsal, Y. (1994). Perceptual load as a major determinant of the locus of selection in visual attention. Perception \& Psychophysics, 56, 183-197.

MiLlER, J. (1987). Priming is not necessary for selective attention failures: Semantic effects of unattended, unprimed letters. Perception \& Psychophysics, 41, 419-434.

MilleR, J. (1991). The flanker compatibility effect as a function of visual angle, attentional focus, visual transients, and perceptual load. Perception \& Psychophysics, 49, 270-288.

Neill, W. T., Terry, K. M., \& VAldes, L. A. (1994, November). Negative priming: Effects of separation and cuing. Paper presented at the annual meeting of the Psychonomic Society, St. Louis.

Neisser, U., \& Becklen, R. (1975). Selective looking: Attending to visually specified events. Cognitive Psychology, 7, 480-494.

P. .QUET, L., \& LoRTIE, C. (1990). Evidence for early selection: Precuing target location reduces interference from same-category distractors. Perception \& Psychophysics, 48, 382-388.

REINER, M. B., \& MORRISON, F. J. (1983). Is semantic interference really automatic? Bulletin of the Psychonomic Society, 21, 271-274.

SCHNEIDER, W., \& FisK, A. D. (1984). Automatic category search and its transfer. Journal of Experimental Psychology: Learning, Memory, \& Cognition, 10, 1-15.

SHIFFrin, R. M., \& SCHNEIDER, W. (1977). Controlled and automatic human information processing: Il. Perceptual learning, automatic attending, and a general theory. Psychological Review, 84, 127-190.

Strasburger, H., Harvey, L. O., JR., \& Rentschler, I. (1991). Contrast thresholds for identification of numeric characters in direct and eccentric view. Perception \& Psychophysics, 49, 495-508.

Yantis, S., \& Johnston, J. C. (1990). On the locus of visual selection: Evidence from focused attention tasks. Journal of Experimental Psychology: Human Perception \& Performance, 16, 135-149.

\section{NOTES}

1. Among the studies reporting evidence for improved selective target processing with increased target-flanker distinctiveness are Baylis and Driver (1992, Experiment 3); Driver and Baylis (1989); B. A. Eriksen and C. W. Eriksen (1974); C. W. Eriksen and B. A. Eriksen (1979); C. W. Eriksen and St. James (1986); Gathercole and Broadbent (1987); Harms and Bundesen (1983); Miller (1991); and Neill, Terry, and Valdes (1994).

2. It should be pointed out that our purpose was not to equate the visual acuity of the near and far flankers, nor that of the target and the flankers, but simply to insure that the far flankers could be adequately perceived. To this end, size scaling based on the cortical magnification factor (Goolkasian, 1994; Strasburger, Harvey, \& Rentschler, 1991) was applied to the stimuli originally employed by Paquet and Lortie (1990). Size scaling was based on the following formula (Strasburger et al., 1991): $S=S_{0}\left(1+0.33 E+0.00007 E^{3}\right)$, where $S$ is the scaled character height, $S_{0}$ is $1.5^{\circ}$, the size of the foveal targets used in Paquet and Lortie (1990), and $E$ is $5^{\circ}$, the retinal eccentricity of the far flankers condition. Accordingly, the scaled characters used in the present experiments were $4^{\circ}$ high

Because we wanted to avoid selection based on size differences, both the target and the flankers were $4^{\circ}$ high. This procedure introduces acuity differences between the target and the flankers that seem unavoidable when horizontal stimulus arrays are used (see Miller, 1991, for a discussion of this issue). Furthermore, we wanted to insure that the size of the attentional focus on the target would be constant for the near and far flankers conditions. On the basis of research showing that target size affects the size of the attentional focus (Laberge, 1983), we decided to use the $4^{\circ}$ high characters for both target-flanker separation conditions.

The suggestion that the far flankers were visible is supported by a pilot study in which stimuli measuring only $2.3^{\circ}$ high were identified very accurately ( $99 \%$ accuracy, which is well above chance responding $\left[\chi^{2}(1)=1,580, p<.01\right]$ ) when they appeared briefly ( $\left.100 \mathrm{msec}\right)$ $5^{\circ}$ in the periphery either to the left or to the right of fixation. Given the larger character size $\left(4^{\circ}\right)$ used in the present study, it would be difficult to argue that possible disappearance of the FVE may be due to the fact that subjects simply could not see the flankers.

3. A mixed-design analysis of variance was carried out on the FVE data to examine the effect of target-flanker separation, attention precuing, flanker category, and correlation block. There was a main effect of target-flanker separation $\left[F(1,376)=12.33, M S_{\mathrm{e}}=1,622, p<.01\right]$ and of correlation block $\left[F(1,376)=38.49, M S_{\mathrm{e}}=1,610, p<.01\right]$. Furthermore, the interaction between these two variables was reliable $\left[F(1,376)=7.65, M S_{\mathrm{e}}=1,610, p<.01\right]$. There were no other significant effects.

4. The results of the far digit flankers cued condition have now been replicated in two unpublished studies conducted in our laboratory using 24 subjects per study and employing characters measuring $2.3^{\circ}$ high. The FVE was found to be equal to $8 \pm 9.09 \mathrm{msec}$ for Study $\mathrm{l}$ and $12 \pm 13.6 \mathrm{msec}$ for Study 2 . These replications reinforce our conclusion that it is possible to eliminate the FVE when the flankers are not in close proximity to the target.

5. A mixed-design ANOVA was carried out on the FVE data to examine the effect of character size, flanker category, and correlation block. There was a main effect of correlation block $[F(1,188)=29.66$, $\left.M S_{\mathrm{e}}=1,209, p<.01\right]$ and a significant character size $\times$ flanker category interaction $\left[F(1,188)=3.97, M S_{\mathrm{e}}=1,532, p<.05\right]$. No other effects were reliable.

6. Some experiments investigating high-load situations are Dark, Johnston, Myles-Worsley, and Farah (1985); Kahneman and Chajczyk (1983); Laberge, Brown, Carter, Bash, and Hartley (1991); Lavie (1995); Neisser and Becklen (1975); and Reiner and Morrison (1983).

\begin{tabular}{|c|c|c|c|c|c|c|}
\hline $\begin{array}{r}\text { Mean } \\
\text { Ea } \\
\end{array}$ & $\begin{array}{l}\text { orrect Rea } \\
\text { and Pe } \\
\text { h Correlati } \\
\text { for Cued C }\end{array}$ & $\begin{array}{l}\text { PPE } \\
\text { on } 1 \\
\text { ent: } \\
\text { Blo }\end{array}$ & $\begin{array}{l}\text { JDIX A } \\
\text { mes (RT } \\
k \text { of Err } \\
k \text { and Fl } \\
\text { ns in Ex }\end{array}$ & , in & $\begin{array}{l}\text { illisecon } \\
\text { Validity } \\
\text { nt } 1\end{array}$ & \\
\hline & & & Fla & kers & & \\
\hline & & & alid & & valid & \\
\hline Separation & Correlation & $\mathrm{RT}$ & $\%$ Error & $\mathrm{RT}$ & $\%$ Error & FVE \\
\hline & & Letter & lankers & & & \\
\hline Near $\left(.3^{\circ}\right)$ & high & 523 & 3.4 & 555 & 4.2 & $32^{*}$ \\
\hline & low & 528 & 3.3 & 533 & 4.1 & 5 \\
\hline $\operatorname{Far}\left(5^{\circ}\right)$ & high & 570 & 3.6 & 583 & 4.4 & 13 \\
\hline & low & 563 & 3.6 & 568 & 3.9 & 5 \\
\hline & & Digit & lankers & & & \\
\hline Near $\left(.3^{\circ}\right)$ & high & 578 & 3.4 & 608 & 4.9 & $30^{*}$ \\
\hline & low & 608 & 4.4 & 607 & 4.1 & -1 \\
\hline $\operatorname{Far}\left(5^{\circ}\right)$ & high & 527 & 3.1 & 541 & 4.0 & 14 \\
\hline & low & 539 & 3.4 & 538 & 3.5 & -1 \\
\hline
\end{tabular}

Note-The flanker validity effect (FVE) was computed by subtracting the valid trials mean latency from the invalid trials mean latency. ${ }^{*} p<.01$. 
APPENDIX B

Mean Correct Reaction Times (RTs, in Milliseconds) and Percentage of Error for

Each Correlation Block and Flanker Validity for No-Cue Conditions in Experiment 1

\begin{tabular}{|c|c|c|c|c|c|c|}
\hline \multirow[b]{3}{*}{ Separation } & \multirow[b]{3}{*}{ Correlation } & \multicolumn{4}{|c|}{ Flankers } & \multirow[b]{3}{*}{ FVE } \\
\hline & & \multicolumn{2}{|c|}{ Valid } & \multicolumn{2}{|c|}{ Invalid } & \\
\hline & & RT & $\%$ Error & RT & $\%$ Error & \\
\hline \multicolumn{7}{|c|}{ Letter Flankers } \\
\hline $\operatorname{Near}\left(.3^{\circ}\right)$ & $\begin{array}{l}\text { high } \\
\text { low }\end{array}$ & $\begin{array}{l}542 \\
564\end{array}$ & $\begin{array}{l}2.5 \\
2.8\end{array}$ & $\begin{array}{l}568 \\
574\end{array}$ & $\begin{array}{l}3.4 \\
2.6\end{array}$ & $\begin{array}{l}26^{*} \\
10\end{array}$ \\
\hline $\operatorname{Far}\left(5^{\circ}\right)$ & $\begin{array}{l}\text { high } \\
\text { low }\end{array}$ & $\begin{array}{l}537 \\
547\end{array}$ & $\begin{array}{l}2.2 \\
2.7\end{array}$ & $\begin{array}{l}557 \\
547\end{array}$ & $\begin{array}{l}2.9 \\
2.7\end{array}$ & $\begin{array}{c}20^{\dagger} \\
0\end{array}$ \\
\hline \multicolumn{7}{|c|}{ Digit Flankers } \\
\hline \multirow[t]{2}{*}{$\operatorname{Near}\left(.3^{\circ}\right)$} & high & 573 & 2.0 & 605 & 3.1 & $33^{*}$ \\
\hline & low & 577 & 2.6 & 579 & 2.3 & 2 \\
\hline \multirow[t]{2}{*}{$\operatorname{Far}\left(5^{\circ}\right)$} & high & 540 & 1.9 & 540 & 2.7 & 0 \\
\hline & low & 530 & 2.0 & 534 & 1.7 & 4 \\
\hline
\end{tabular}

Note-The flanker validity effect (FVE) was computed by subtracting the valid trials mean latency from the invalid trials mean latency. ${ }^{*} p<.01 . \quad{ }^{+} p<.05$.

APPENDIX C

Mean Correct Reaction Times (RTs, in Milliseconds) and Percentage of Error for Each Correlation Block and Flanker Validity in Experiment 2

\begin{tabular}{|c|c|c|c|c|c|c|}
\hline \multirow{3}{*}{$\begin{array}{c}\text { Character } \\
\text { Size }\end{array}$} & \multirow[b]{3}{*}{ Correlation } & \multicolumn{4}{|c|}{ Flankers } & \multirow[b]{3}{*}{ FVE } \\
\hline & & \multicolumn{2}{|c|}{ Valid } & \multicolumn{2}{|c|}{ Invalid } & \\
\hline & & RT & $\%$ Error & RT & \% Error & \\
\hline \multicolumn{7}{|c|}{ Letter Flankers } \\
\hline \multirow[t]{2}{*}{ Small } & high & 564 & 2.7 & 607 & 4.6 & $43^{*}$ \\
\hline & low & 581 & 3.2 & 588 & 3.4 & 7 \\
\hline \multirow{2}{*}{ Large } & high & 536 & 2.7 & 558 & 4.4 & $22^{*}$ \\
\hline & low & 552 & 2.9 & 560 & 3.0 & 8 \\
\hline \multicolumn{7}{|c|}{ Letter Flankers } \\
\hline \multirow[t]{2}{*}{ Small } & high & 569 & 3.2 & 586 & 4.7 & $17^{*}$ \\
\hline & low & 578 & 3.3 & 581 & 3.3 & 3 \\
\hline \multirow[t]{2}{*}{ Large } & high & 558 & 2.3 & 581 & 3.3 & $23^{*}$ \\
\hline & low & 577 & 2.8 & 586 & 2.9 & 9 \\
\hline
\end{tabular}

Note-The flanker validity effect (FVE) was computed by subtracting the valid trials mean latency from the invalid trials mean latency. ${ }^{*} p<.01$.

(Manuscript received September 17, 1995; revision accepted for publication March 15, 1996.) 